\title{
Assessing stemness and proliferation properties of the newly established colon cancer 'stem' cell line, CSC480 and novel approaches to identify dormant cancer cells
}

\author{
FAISAL ALOWAIDI $^{1}$, SAEED MUJAHID HASHIMI ${ }^{2}$, NAIF ALQURASHI ${ }^{2}$, REEM ALHULAIS ${ }^{4}$, \\ SASO IVANOVSKI ${ }^{4}$, BERNADETTE BELLETTE ${ }^{3}$, ADRIAN MEEDENYIA ${ }^{4}$, \\ ALFRED LAM $^{4}$ and STEPHEN WOOD ${ }^{3}$ \\ ${ }^{1}$ Department of Pathology and Laboratory Medicine, College of Medicine and University Hospitals, \\ King Saud University, Riyadh $11461{ }^{2}$ Department of Basic Science, Biology Unit, \\ Deanship of Preparatory Year and Supporting Studies, Imam Abdulrahman Bin Faisal University, Dammam 34212, \\ Kingdom of Saudi Arabia; ${ }^{3}$ Griffith Institute for Drug Discovery, Griffith University, Brisbane, Queensland 4111; \\ ${ }^{4}$ Menzies Health Institute Queensland, Griffith University, Gold Coast Campus, Queensland 4222, Australia
}

Received October 5, 2017; Accepted March 7, 2018

DOI: $10.3892 / o r .2018 .6392$

\begin{abstract}
To date two questions that remain unanswered regarding cancer are the following: i) how is it initiated, and ii) what is the role that cancer stem cells (CSCs) play in the disease process? Understanding the biology of CSCs and how they are generated is pivotal for the development of successful treatment regimens. To date, the lack of a representative cell model has prevented the successful identification and eradication of CSCs in vivo. The current methods of CSC identification are dependent on the protocol used to generate these cells, which has introduced variation and made the identification process more complicated. Furthermore, the list of possible markers is increasing in complexity. This is further confounded by the fact that there is insufficient information to determine whether the cells these markers detect are truly self-renewing stem cells or, instead, progenitor cells. In the present study, we investigated a novel cell line model, CSC480, which can be employed to assess CSC markers and for testing novel therapeutic regimens. CSC480 cells have been revealed to express markers of CSCs such as CD44, ALDH1 and Sox2, that have lower expression in the SW480 cell line. CSC480 cells also expressed higher levels of the cancer resistance
\end{abstract}

Correspondence to: Dr Stephen Wood, Griffith Institute for Drug Discovery, Nathan Campus, Griffith University, Brisbane, Queensland 4111, Australia

E-mail: s.wood@griffith.edu.au

Abbreviations: FHC, fetal human colon cell line; ALDH1, aldehyde dehydrogenase family 1 member A1; ABCG2, ATP-binding cassette sub-family G member 2; EpCAM, epithelial cell adhesion molecule

Key words: cancer stem cells, CSC480 cell line, FHC cell line, EdU, ALDH1, CD44, dormancy marker, ABCG2 and had higher proliferative and growth capacity than SW480 cells. In the present study, we also evaluated a novel approach to identify different cell types present in heterogeneous cancer cell populations according to their proliferative ability using the proliferation marker 5-ethynyl-2'-deoxyuridine (EdU). Furthermore, using EdU, we identified dormant cells with a modified label-retaining cell (LRC) protocol. Through this novel LRC method, we assessed newly discovered markers of stemness to ascertain their capability to identify quiescent from dividing CSCs. In conclusion, the CSC480 cell line was an important model to be used in unravelling the underlying mechanisms that control fast-dividing and partially self-renewing stem cells (SCs) that may give rise to cancer.

\section{Introduction}

It has recently been demonstrated that the recurrence of cancer in vivo was attributable to the self-renewal capacity of so called CSCs or cancer initiating cells (CICs) (1). It has also been revealed that resistance to conventional therapeutic regimens in vitro and in vivo was a feature of these cells (2). Thus, it was crucial to assess the self-renewal of CSC480 cells. A particular set of genes, including ALDH1A1 and CD44 are known for their role in maintaining the self-renewal of CSCs.

CD44 is one of the most common surface markers used to identify CSCs (3). The CD44 glycoprotein is a receptor for a major component of the extracellular matrix, hyaluronan (HA) (4). In many cancers, binding of HA to CD44 activates multiple receptor tyrosine kinases, including epidermal growth factor receptor (EGFR) and ERBB2 (5). HA binding to CD44 leads to activation of the MAPK and PI3K/AKT pathways, resulting in increased proliferation and survival (4). Inhibition of CD44-HA binding has been shown to prevent tumor formation in colorectal cancer (6). CD44, either alone or in combination with other surface markers, has been used to identify and isolate cells with stem cell properties from colon cancer tissue (7). 
Aldefluor is a new flow cytometric methodology that assesses ALDH activity in viable cells. This method was initially used to sort hematopoietic cells $(8,9)$. ALDH1 activity was combined with CD34 expression to identify distinct hematopoietic stem and progenitor cell subpopulations (10). Based on its role in the identification of haematopoietic stem cells, it has been hypothesised that ALDH1 is plausibly useful to identify CSCs from multiple myeloma and leukaemia patients. This was supported by the fact that isolated ALDH bright cells exhibit high tumorigenicity when inoculated into non-obese diabetic/severe combined immunodeficiency (NOD/SCID) mice $(11,12)$. In addition, these ALDH bright cells exhibited the traditional features of a stem cell such as a slow proliferation rate.

Dormancy is a process that CSCs use to evade the immune system before or after metastasis. It is believed that dormant metastatic cells originate from a pool of quiescent cells. Being non-proliferative, resting in the quiescent state and losing apoptotic potential, as well as retaining LRC markers or expressing stem-like markers are defining features of these cells (13). Research hypotheses have been developed to investigate the interchangeable state between slow and fast proliferating cancer cells. One of the major research questions was to address this process in dormant cancer cells after metastasis, in order to determine if it was restricted to metastasis or also occured in the primary tumor (14). CSCs survive extreme micro-environmental conditions long-term by being dormant. However, the decision to remain dormant or proliferate is coordinated by extracellular conditions including immune reactions to antitumor treatment and variations in angiogenic processes $(15,16)$. Key intracellular checkpoints controlling CSC entry and exit from quiescence include modifications in the cell cycle (17). Understanding the behaviour of 'dormant' CSCs and unravelling approaches to identify them are critical in the treatment of cancer.

Several studies have claimed that proliferation markers like BrdU can be used as label-retaining markers for the identification of slow dividing SCs (18). We exploited the properties of the proliferation marker EdU, which is incorporated into the DNA of actively dividing cells in the same manner as BrdU. Upon cell division, it distributes equally to both daughter cells. Therefore, EdU fluorescence decreases with each round of DNA synthesis and cell division, however it is retained at original levels in non or slow dividing cells (19).

The aim of the present study was to assess and characterise the stemness properties of a new putative colorectal adenocarcinoma cancer stem cell model. These cells were established and promoted by Biomedicure (San Diego, CA, USA), however there was no available information about their properties. However, the methods used to generate the cells did not describe their characteristics (20). Thus, the need arose to verify them independently. As aforementioned, CSCs were supposed to display defining characteristics and these were investigated accordingly.

In the present study, we assessed the stemness properties and proliferative capacity of CSC480 cells using in vitro techniques. Furthermore, this study presented a new approach for identifying different populations in heterogenous cancers. Finally, we hypothesised that we could assess the utility of EdU for the characterisation of an infrequently cycling (i.e. EdU retaining), tumor-initiating, sub-population in human colon cancer cells.

\section{Materials and methods}

Cell culture. Three colon cell lines were used. The normal fetal human colon epithelial cell line FHC [American Type Culture Collection (ATCC) Manassas, VA, USA], the grade 3-4 colon adenocarcinoma cell line SW480 (ATCC) and colorectal cancer stem cell line CSC480 (Biomedicure) (20). The SW480 and CSC480 cells were maintained in Dulbecco's modified Eagle's medium (DMEM)-high glucose media (Gibco; Thermo Fisher Scientific, Waltham, MA, USA) supplemented with $10 \%(\mathrm{v} / \mathrm{v})$ fetal bovine serum (FBS; Gibco; Thermo Fisher Scientific) $100 \mathrm{~g} / \mathrm{ml}$ streptomycin, $100 \mathrm{U} / \mathrm{ml}$ penicillin and cultured in a humidified atmosphere of $5 \% \mathrm{CO}_{2}$ at $37^{\circ} \mathrm{C}$. The $\mathrm{FHC}$ cell line was propagated using DMEM/F12 (Gibco; Thermo Fisher Scientific) supplemented with $25 \mathrm{mM}$ HEPES, $10 \mathrm{ng} / \mathrm{ml}$ cholera toxin, $0.005 \mathrm{mg} / \mathrm{ml}$ insulin, $0.005 \mathrm{mg} / \mathrm{ml}$ transferrin, $100 \mathrm{ng} / \mathrm{ml}$ hydrocortisone (Sigma-Aldrich Merck KGaA; Darmstadt, Germany) and 10\% FBS (Gibco; Thermo Fisher Scientific).

\section{Flow cytometry}

ALDH activity assessment. ALDH activity was analysed using the Aldefluor assay according to the manufacturer's instructions (StemCell Technologies, Vancouver, BC, Canada). Approximately $1 \times 10^{6}$ cells were used for analysis. Firstly, the cells were detached using Accutase dissociation reagent (Innovative Cell Technologies, San Diego, CA, USA). The cells were then washed three times with PBS and centrifuged at $250 \mathrm{x} \mathrm{g}$ for $2 \mathrm{~min}$ for each wash. Cell concentration was determined through trypan blue exclusion. The cells were then resuspended using Aldefluor-activated reagent Bodipy-aminoacetaldehyde (BAAA; $1 \mu \mathrm{mol} / 1$ per $1 \times 10^{6}$ cells). Half of the cell suspension was transferred to another tube containing diethylaminobenzaldehyde (DEAB) solution $(50 \mathrm{mmol} / \mathrm{l})$ and incubated for one hour at $37^{\circ} \mathrm{C}$ to deactivate the Adlefluor-activated reagent. The cells were then pelleted by centrifugation at $250 \mathrm{xg}$ for $2 \mathrm{~min}$, the supernatant was removed and the cells were resuspended in $200 \mu 1$ of $1 \%$ BSA/Aldefluor buffer.

CD44 flow cytometric analysis. For the analysis of the CD44 expression, the cells were detached using Accutase dissociation reagent (Innovative Cell Technologies). The cell suspension was washed twice with PBS and centrifuged at $250 \mathrm{x}$ g for $2 \mathrm{~min}$ for each wash. The cells were incubated with mouse anti-human CD44-FITC primary antibody (cat. no. MHCD4401; Invitrogen; Thermo Fisher Scientific) or mouse isotype matched control (cat. no. 11-4724-42; eBioscience; Thermo Fisher Scientific; the dilution for both antibodies is $5 \mu \mathrm{l} / 1 \times 10^{6}$ cells suspended in $400 \mu \mathrm{l}$ of $1 \% \mathrm{BSA} / \mathrm{PBS}$ solution) on ice, in the dark for $30 \mathrm{~min}$. Subsequently, the cell suspensions were centrifuged for $10 \mathrm{~min}$ at $100 \mathrm{x}$ g at $4^{\circ} \mathrm{C}$, the supernatants were removed, the cells were resuspended in $1 \%$ BSA in PBS and incubated with 7-AAD nuclear stain (eBioscience) on ice for $5 \mathrm{~min}$. The cells were then analysed via flow cytometry.

Flow cytometric analysis. The flow cytometric analysis was performed on a FACSAria flow cytometer (BD Biosciences, Franklin Lakes, NJ, USA). The rate of acquisition was set 
Table I. Primer sequences.

\begin{tabular}{lll}
\hline Gene & \multicolumn{1}{c}{ Forward } & Reverse \\
\hline ABCG2 & GTTCTCAGCAGCTCTTCGGCTT & TCCTCCAGACACACCACGGATA \\
CD44 & CCAGAAGGAACAGTGGTTTGGC & ACTGTCCTCTGGGCTTGGTGTT \\
Ki67 & GAAAGAGTGGCAACCTGCCTTC & GCACCAAGTTTTACTACATCTGCC \\
EpCAM & GCCAGTGTACTTCAGTTGGTGC & CCCTTCAGGTTTTGCTCTTCTCC \\
ALDH1A & CGGGAAAAGCAATCTGAAGAGGG & GATGCGGCTATACAACACTGGC \\
SOX2 & GCTACAGCATGATGCAGGACCA & TCTGCGAGCTGGTCATGGAGTT \\
NANOG & CTCCAACATCCTGAACCTCAGC & CGTCACACCATTGCTATTCTTCG \\
GAPDH & GTCTCCTCTGACTTCAACAGCG & ACCACCCTGTTGCTGTAGCCAA
\end{tabular}

to $<10,000$ events per second. The logarithmic amplification was used for EdU fluorescence. For the detection of EdU with Alexa Fluor 647, 633/635 nm excitation with the red emission filter $(660 / 20 \mathrm{~nm})$ was used, while for the detection of CD44 with FITC, $488 \mathrm{~nm}$ excitation with a green filter emission filter (530/30 nm) was used. A whole cell gate on forward vs. side scatter was constructed to exclude debris, doublets and aggregates. This gate was used for all subsequent analyses.

Immunofluorescence staining. SW480 and CSC480 cells were seeded into 8-well chamber slides at a density of 10,000 cells/well. The cells were pulsed with $10 \mu \mathrm{M}$ EdU for $2 \mathrm{~h}$ (Invitrogen Life Technologies). Subsequently, they were fixed with $4 \%$ formaldehyde and stained using Click-iT EdU Imaging kit (Invitrogen Life Technologies) following the manufacturer's protocol. The cells were washed three times with $1 \mathrm{X}$ phosphate buffered saline (PBS) and were blocked in $1 \%$ bovine serum albumin (BSA) in $1 \mathrm{X}$ PBS. Subsequently, the cells were incubated with mouse anti-human CD44 monoclonal antibody (1:100 dilution; cat. no. 3570; Cell Signaling Technology, Inc., Danvers, MA, USA) or mouse isotype matched control (cat. no. 12-4724-42; eBioscience) at room temperature, in the dark for $30 \mathrm{~min}$. The primary antibody was withdrawn and cells were washed three times as above-mentioned. Then, the cells were incubated with donkey anti-mouse Alexa Fluor 594 secondary antibody (1:1,000; cat. no. AF594; Abcam, Cambridge, MA, USA). They were washed as above-mentioned and counterstained with Vectashield/DAPI (cat. no. H-1200; Vector Laboratories, Burlingame, CA, USA).

Image acquisition and analysis. Immunofluorescence images were acquired using an AxioImager Z1 fluorescence microscope (Carl Zeiss, Inc., Thornwood, NY, USA) and an Axiocam camera (Carl Zeiss, Inc.). Images were processed using AxioVision 4.6.3 (Carl Zeiss, Inc.) digital image editing software and adjusted for brightness and contrast only using Adobe Photoshop software.

RNA extraction. The cells in T75 flasks (Corning Incorporated, Corning, NY, USA) were washed twice with $4 \mathrm{ml}$ Dulbecco's phosphate-buffered saline (DPBS) and incubated with 3-4 ml trypsin (Gibco; Thermo Fisher Scientific) for $3-5 \mathrm{~min}$ at $37^{\circ} \mathrm{C}$. Once detached, the trypsin was inactivated by the addition of an equal amount of fresh media containing serum and the cells were pelleted by centrifugation at $250 \mathrm{x}$ g for $5 \mathrm{~min}$. The cells were washed with 2-3 ml of PBS (depending on the pellet size) and pelleted in a $1.5 \mathrm{ml}$ Eppendorf tube by centrifugation at $300 \mathrm{x}$ g for $5 \mathrm{~min}$ at $4^{\circ} \mathrm{C}$. The cell pellets were stored at $-80^{\circ} \mathrm{C}$ until processing.

Total RNA was extracted using the RNeasy kit (Qiagen, Inc., Valencia, CA, USA) according to the manufacturer's instructions. The cell pellets (typically $\sim 1 \times 10^{6}$ cells) were resuspended in $350 \mu \mathrm{l}$ lysis buffer and disrupted by vortexing vigorously for $15 \mathrm{sec}$. Subsequently, $350 \mu \mathrm{l}$ of $70 \%$ ethanol was added before each sample was transferred to an RNeasy spin column. Following wash steps, the RNA was eluted in $30 \mu \mathrm{l}$ RNase/DNase-free water. The amount and purity of the RNA was determined by measuring absorbance at $260 \mathrm{~nm}$ (A260) and $280 \mathrm{~nm}$ (A280) on a NanoDrop spectrophotometer (Thermo Fisher Scientific, Wilmington, DE, USA). An A260/A280 ratio of 1.8-2.0, indicating RNA free of contaminating protein or phenol, was obtained for all samples. RNA was stored at $-80^{\circ} \mathrm{C}$.

cDNA synthesis. cDNA was synthesized with miSript reverse transcription kit (Qiagen) according to the manufacturer's instructions. Briefly, to perform cDNA synthesis, up to $1 \mu \mathrm{g}$ of RNA was mixed with $5 \mathrm{X}$ miScript RT buffer, $1 \mu \mathrm{l}$ of miScript Reverse Transcriptase Mix and adjusted with water to a total of $20 \mu \mathrm{l}$. The reaction was mixed and incubated at $37^{\circ} \mathrm{C}$ for $60 \mathrm{~min}$ and then incubated at $95^{\circ} \mathrm{C}$ for $5 \mathrm{~min}$ to inactivate the miScript Reverse Transcriptase Mix. cDNA samples were then stored at $-20^{\circ} \mathrm{C}$.

Real-time quantitative PCR. Quantitative real-time PCR was performed using the iCycler iQ5 Real-Time PCR system (Bio-Rad Laboratories, Inc., Hercules, CA, USA). Quantitative gene expression was determined for ABCG2, CD44, Ki67, EpCAM, ALDH1A and SOX2 (OriGene Technologies, Inc., Rockville, MD, USA). The primer sequences are listed in Table I.

The results were normalized to the housekeeping gene GAPDH (OriGene Technologies, Inc.). Real-time PCR was performed according to the following cycling protocol: 1 cycle at $95^{\circ} \mathrm{C}$ for $10 \mathrm{~min}$, followed by 42 cycles at $94^{\circ} \mathrm{C}$ for $10 \mathrm{sec}$ and $60^{\circ} \mathrm{C}$ for $10 \mathrm{sec}$.

EdU incorporation. The cells were exposed to a $2 \mathrm{~h}$ pulse of $10 \mu \mathrm{M}$ EdU (Invitrogen Life Technologies). Retention 
A

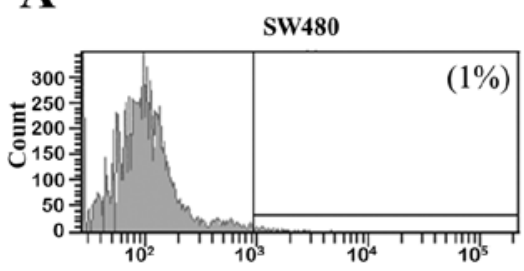

Isotype-FITC fluorescence intensity

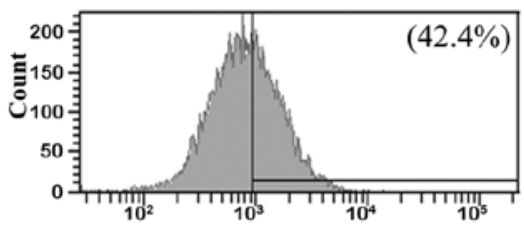

CD44-FITC fluorescence intensity

C

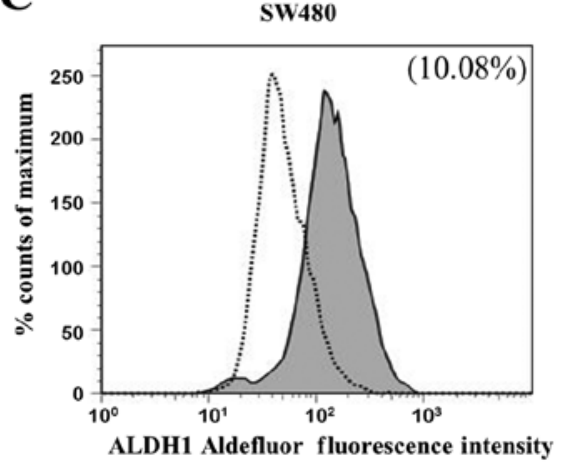

CSC480

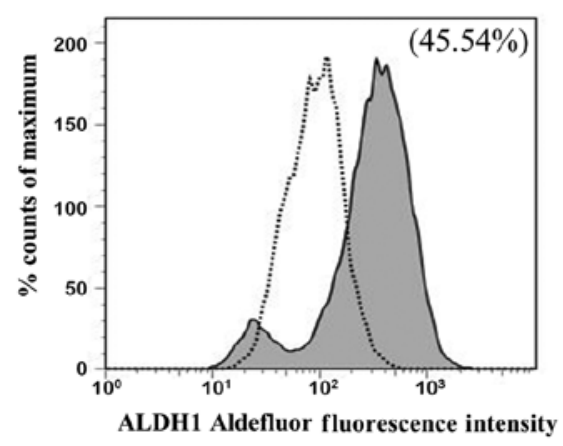

B

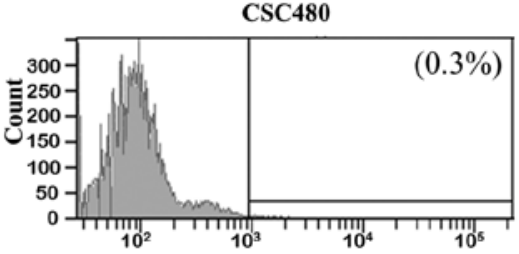

Isotype-FITC fluorescence intensity

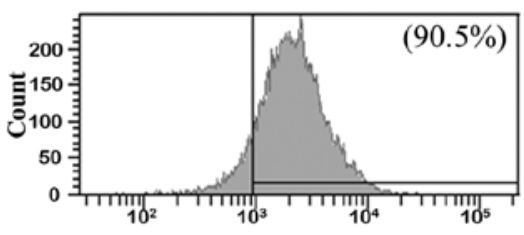

CD44-FITC fluorescence intensity

D
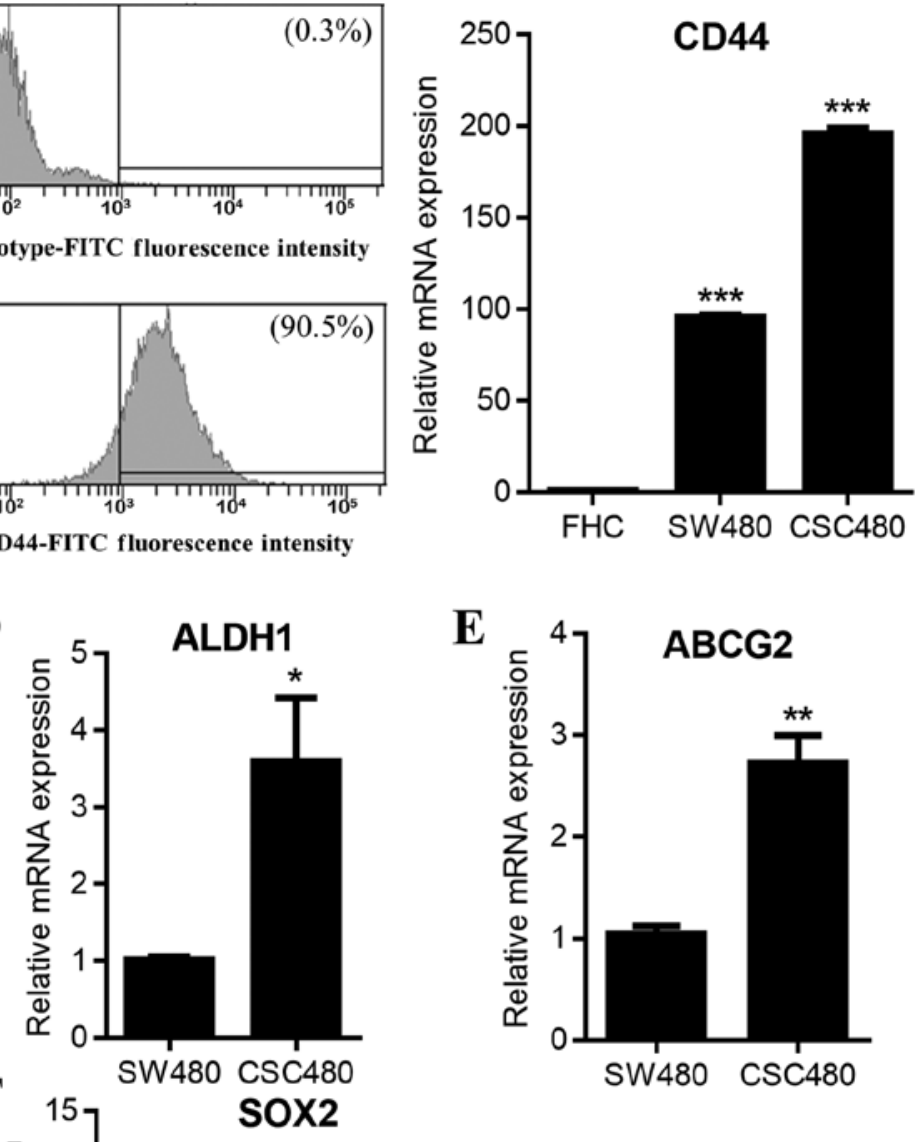

$\mathbf{E}$

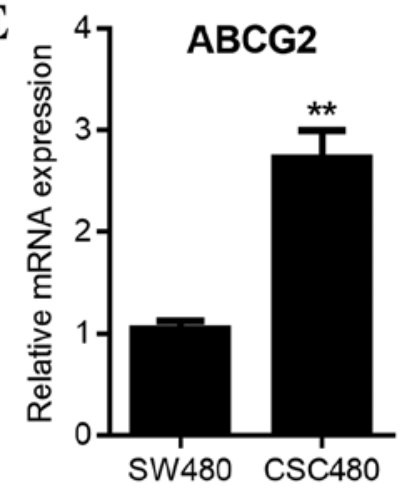

Figure 1. Phenotypic and molecular characterisation of the CSC480 cancer cell line. (A) Flow cytometric analysis of CD44 in CSC480 cell line. The scatter plots on the top row represent isotype-FITC labelled control group and on the bottom row represent CD44-FITC group. There was considerable increase in CD44-FITC intensity in CSC480 cell lines as compared to the control cancer cell line. (B) The expression of CD44 mRNA levels in CSC480, SW480 and FHC cells. Data are mean \pm SEM, $n=3$; statistical analysis, one-way ANOVA; ${ }^{* * *} \mathrm{P}<0.001$ to FHC. (C) Analysis of ALDH1 in CSC480 cells. Scatter plots on the left show flow cytometric analysis of ALDH1 using Aldefluor assay. The area under the dotted line represents Aldefluor-treated cells while the area under the solid line represents ALDH1 Aldefluor-treated cells. (D) The bar graph on the right displays ALDH1 mRNA expression levels in CSC480 cell line, compared with SW480 control cell line. Data are mean \pm SEM, $n=3$; statistical analysis, Student's t-test; ${ }^{*}<<0.05$. (E) The expression of ABCG2 mRNA levels in CSC480 cells. Data are mean \pm SEM, $n=3$; statistical analysis, Student's t-test; ${ }^{* *} \mathrm{P}<0.01$. (F) Bar graph on the right represents the expression of SOX2 mRNA levels in CSC480 cell lines compared to cancer cell line, SW480 and normal colon cell line, FHC used as controls. Data are mean \pm SEM, $\mathrm{n}=3$; statistical analysis, one-way ANNOVA; ${ }^{* * *} \mathrm{P}<0.001$ compared to FHC.

was assessed in SW480 and CSC480 cell lines at different time-point post-labelling $(24,48,72$ and $96 \mathrm{~h})$ after a $24 \mathrm{~h}$ EdU exposure $(10 \mu \mathrm{M})$. Labelling was performed according to the manufacturer's instructions (Click-iT ${ }^{\mathrm{TM}}$ EdU; Invitrogen Life Technologies).

MTT proliferation assay. Three hours before each of the time-points, $20 \mu 1$ of 3-(4,5-dimethylthiazol-2-yl)-2,5-diphe- nyltetrazolium bromide (MTT) solution $(5 \mathrm{mg} / \mathrm{ml}$ in PBS) (Sigma-Aldrich; Merck KGaA) was added into each well and the cells were incubated at $37^{\circ} \mathrm{C}$ for a further $3 \mathrm{~h}$. The medium was removed and $100 \mu 1$ of DMSO was added into each well. The plate was gently rotated on an orbital shaker for $10 \mathrm{~min}$ to completely dissolve the precipitate. The absorbance was detected at $570 \mathrm{~nm}$ with a microplate reader (POLARstar Omega; BMG Labtech, Offenburg, Germany). 


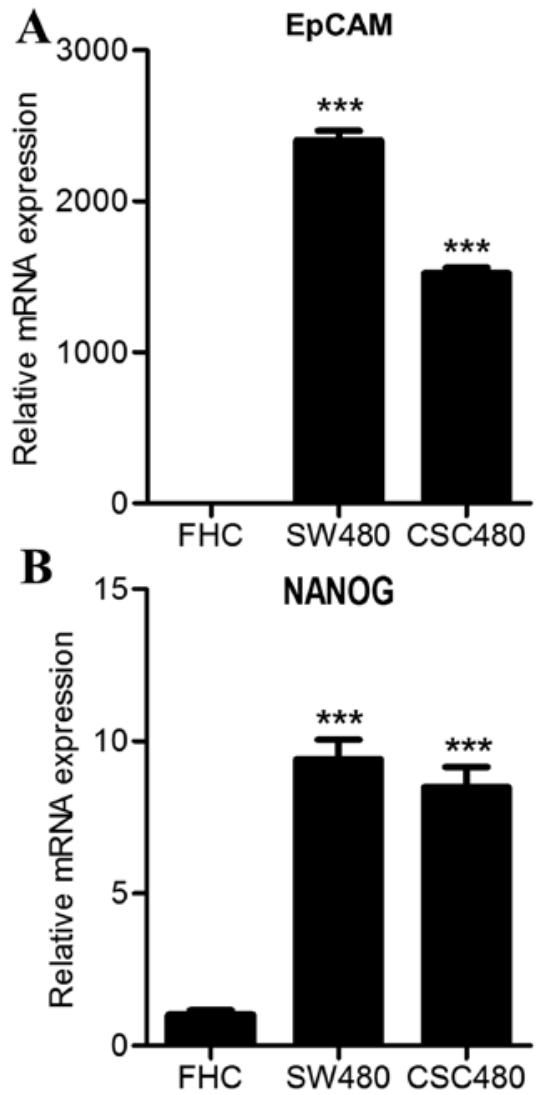

Figure 2. Expression analysis of EpCAM and NANOG mRNA levels in CSC480 cancer cell line. (A) The upper bar graph represents the expression of EpCAM mRNA levels and (B) the bottom bar graph represents the expression of NANOG mRNA levels in CSC480 cancer cells compared to SW480 cancer cells and FHC normal colon cells. ${ }^{* * *} \mathrm{P}<0.001$.

Statistical analysis. GraphPad Prism 6 software suite (GraphPad Software, Inc., La Jolla, CA, USA) was used to perform statistical analysis using Student's t-test or one-way ANOVA. The experiments were conducted in triplicate and data are presented as the means \pm standard error of mean (SEM). $\mathrm{P}<0.05$ was considered to indicate a statistically significant difference.

\section{Results}

Phenotypic and molecular assessment of the CSC480 cells compared to SW480 cells. Using well-characterized biomarker assays, the stem cell-like characteristics of the CSC480 cell line were assessed compared to the parental cell line, SW480. It was observed that these markers vary in their expression between the two cell lines. CSC480 cells expressed significantly higher CD44 protein (90.5\%) than SW480 cells (42.4\%) (Fig. 1A). Furthermore, CSC480 cells expressed twice the amount of CD44 mRNA than SW480 cells while FHC 'normal' colon epithelial line expressed little if any, CD44 ( $\mathrm{P}<0.001$; Fig. 1B). CSC480 cells also expressed higher $A L D H 1$ activity (45.54\%) compared with SW480 cells (10.08\%) (Fig. 1C). We also found that CSC480 expressed four times more $A L D H 1 \mathrm{mRNA}(\mathrm{P}<0.05)$ (Fig. 1D) and three times more $A B C G 2(\mathrm{P}<0.01)$ (Fig. 1E) than $\mathrm{SW} 480$ cells CSC480 cells expressed an $\sim 1.2$-fold increase in Sox2 mRNA than SW480 cells $(\mathrm{P}<0.001)($ Fig. $1 \mathrm{~F})$.
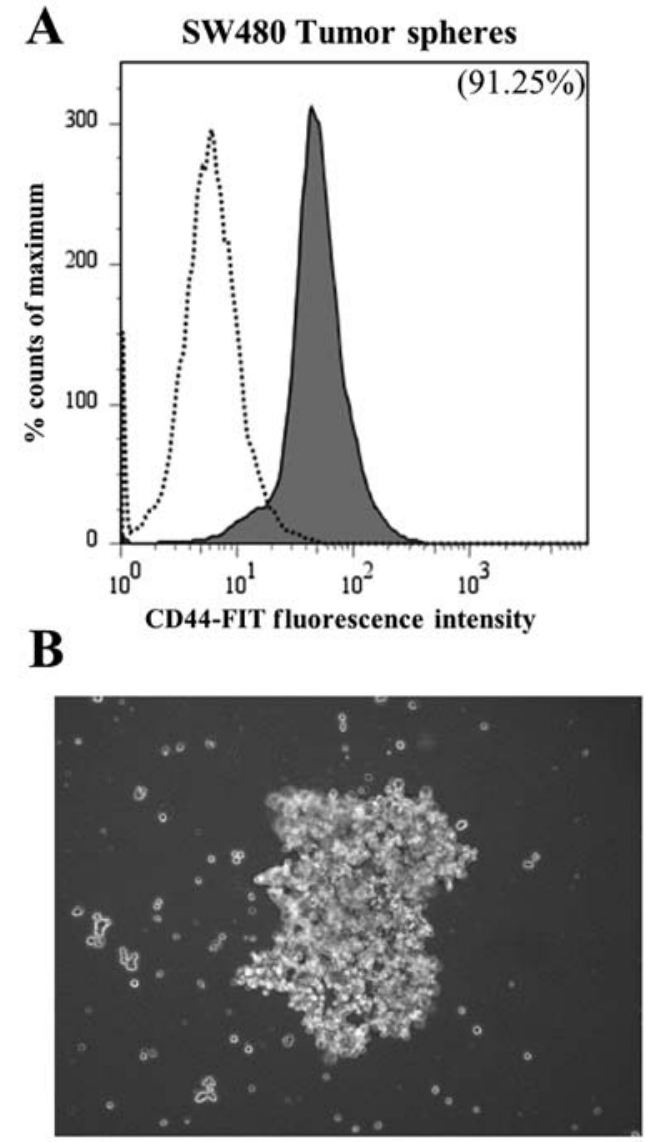

Figure 3. Assessing tumor-sphere enrichment using CD44 stem-like/progenitor marker in SW480 cells. (A) SW480 tumor-spheres generated using a conditioned medium were subjected to flow cytometric analysis. Graphical presentation of CD44-FITC fluorescence intensity is displayed. The area under the dotted line represents isotype-FITC fluorescence intensity as the control, while the area under the solid line represents CD44-FITC fluorescence intensity. (B) Image of SW480 tumor sphere.

Notably, EpCAM, a marker for isolating self-renewing colorectal cancer cells, demonstrated $\sim 1.5$-fold higher expression in SW480 cells compared to CSC480 cells (Fig. 2). The embryonic stem cell gene, NANOG, was highly expressed in both cell types compared to FHC cells. Both were significantly different from FHC cells $(\mathrm{P}<0.001)$ (Fig. 2).

Comparing CSC-480 cells with SW480 tumor-sphere cells. To determine if the established cell line, CSC480, presented similar expression of the CD44 marker compared to the conventional method, we used an established method for enriching cancer cells into a stem-like phenotype (21). SW480 cells were exposed to an enrichment medium in low adherent culture to form tumor spheres and analyzed for CD44 expression. Flow cytometric analysis revealed that following tumor-sphere formation, SW480 cells expressed CD44 to a similar degree as CSC480 cells (91.25\%) (Fig. 3; to be compared with Fig. 1A).

Assessing the proliferation of CSC480 cells compared to SW480 cells. CSC480 cells demonstrated enhanced proliferative capacity compared to SW480 cells. Ki67, a well-established proliferation marker, was used to assess the proliferative capacity of the cell lines. It was found that CSC480 cells expressed Ki67 at $160 \%$ of SW480 levels $(\mathrm{P}<0.001)$ (Fig. 4A). 

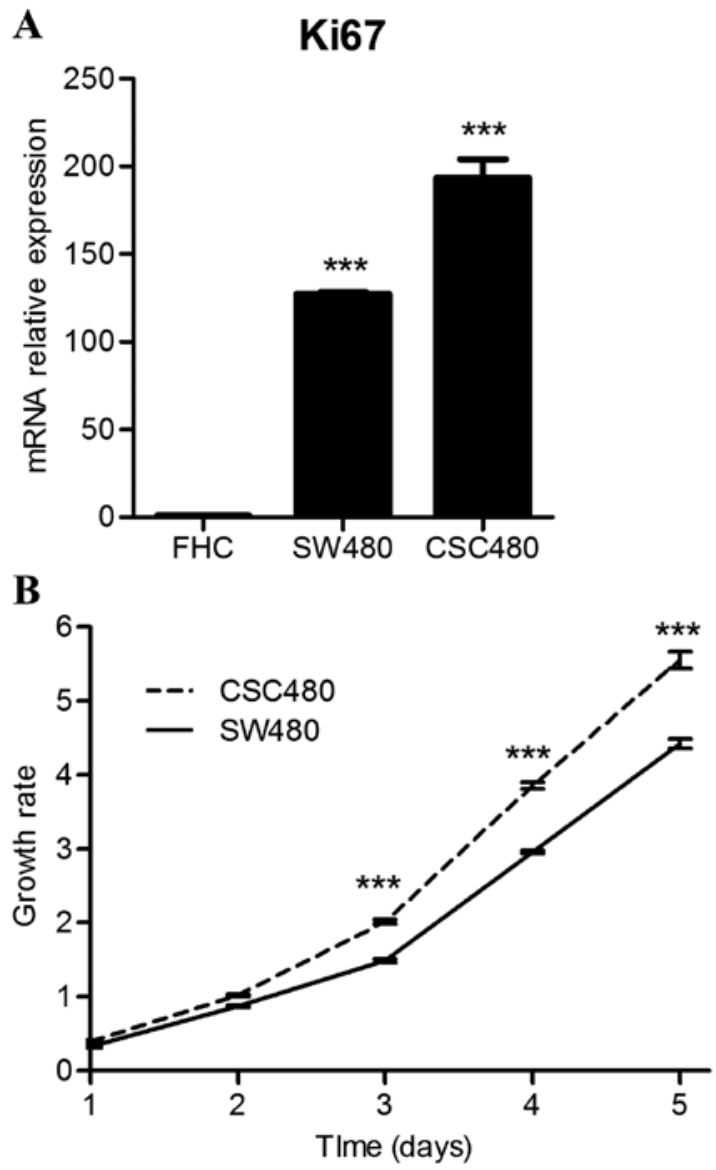

Figure 4. Assessing the proliferation capacity of CSC480 cancer cells. (A) The bar graph of the expression analysis of the cell proliferation marker, Ki-67 mRNA level. The mean Ki67 mRNA levels in CSC480 cancer cells were compared to SW480 cancer cells and FHC fetal colon cells as controls. Data are mean $\pm \mathrm{SEM}, \mathrm{n}=3$; statistical analysis, one-way ANOVA, Brown-Forsythe test; ${ }^{* * *} \mathrm{P}<0.001$. (B) Graphical presentation of MTT assay for cell growth and viability in CSC480 cells compared to SW480 cells. Data are mean \pm SEM, $\mathrm{n}=3$; statistical analysis, one-way ANOVA, Brown-Forsythe test; ${ }^{* * *} \mathrm{P}<0.001$.

Furthermore, MTT assays used to assess the cell growth rate over a five-day period revealed that CSC480 cells grew 10-15\% faster than SW480 cells (Fig. 4B). There was significant increase in the cell growth rate of CSC480 cells on day 3,4 and $5(\mathrm{P}<0.001)$.

EdU can identify different populations of cells in the CSC480 cell line. EdU is a well-studied marker for labelling cells in the $\mathrm{S}$ phase. Research has revealed different uses for this marker, including the use of EdU incorporation to identify cells subsequently residing in a quiescent state (dormancy) (22). Exposing CSC480 cells to EdU for $2 \mathrm{~h}$ revealed that the cells were divided into five different populations according to their EdU fluorescent intensity and CD44 expression. Four CD44 stained populations were labelled with EdU, while only a minor population was positive for CD44 alone. This EdU-negative and CD44-positive population may represent the 'true' stem-like cell population. We observed that EdU was able to divide SW480 cells into similar populations ratios as well (Fig. 5A). Immunofluorescence staining demonstrated a similar trend when EdU was combined with CD44. It has demonstrated that EdU stained CD44-positive population with variable intensities. The highly expressing EdU population were lower in
CD44 expression. Conversely, highly CD44 expressing cells revealed low to diminished EdU labeling intensity (Fig. 5B). This indicated that EdU may be used to identify different populations in a heterogeneous cancer population according to their division state.

FHC cell line for assessing quiescence markers and the resistance to therapeutic regimens in cancer compared to normal cells. We used FHC gene expression to calibrate stem cell-like characteristics in CSC480 cells compared to SW480 cell line. FHC cells were very slow in division, which may be an indicator that they were resting at the quiescence stage. The gene expression of markers normally associated with stem cell-like properties was analysed in FHC cells.

Notably, we found that the FHC cells expressed high levels of the known stem cell marker ALDH1, whereas the CSC480 and SW480 cells expressed low levels. FHC cells expressed 1,400 -fold more $A L D H 1$ than SW480 cells $(\mathrm{P}<0.01)$ and $\sim 400$-fold more than the CSC480 cells $(\mathrm{P}<0.001)$ (Fig. 6). This indicated that FHC could be used for assessing markers of slow-cycling cancer cells and that $A L D H 1$ may be a marker of quiescence. Furthermore, $A B C G 2$, a cancer-resistance marker, was upregulated in FHC compared to both CSC480 and SW480 cells. FHC cells were associated with 80 -fold more $A B C G 2$ mRNA than SW480 cells $(\mathrm{P}<0.001)$ and 30 -fold more $A G C G-2$ mRNA than CSC480 cells $(\mathrm{P}<0.01)$ (Fig. 7). Combining this observation with data from other studies indicated that this approach may be used for identifying quiescent cells.

To further confirm the slow division of FHC cells, we treated them with the EdU proliferation marker to track their division rate and we observed them under fluorescent microscopy. Our observation of FHC cells revealed no EdU incorporation, which indicated that these cells had slow dividing nature.

CD44-positive/EdU label retaining cells are slow-dividing colon cancer cells. To identify the actively dividing cells from non-dividing cells, CSC480 and SW480 cells were exposed to EdU for $24 \mathrm{~h}$ and harvested at different time-points. Four distinct populations of cells were observed (Fig. 8). CSC480 cells collected at 24 and $48 \mathrm{~h}$ revealed a high retention of EdU and more CD44 expression (85.84 and 85.28\%) than SW480 cells (74 and 77\%). At both time-points, CSC480 cells expressed more CD44 than SW480 cells $( \pm 91.41$ and $\pm 78.98 \%$, respectively). Conversely, EdU was retained in the cells harvested at two days, showing similar ratios of labeled cells in both cell lines (SW480 cells, $92.51 \%$ and CSC480 cells, 93.88\%). Both cell types harvested after $72 \mathrm{~h}$ demonstrated a significant loss of EdU in the CD44-positive population (SW480 cells, 60.80\% and CSC480 cells, 66.36\%). SW480 cells collected after $96 \mathrm{~h}$ in culture revealed that $\mathrm{CD} 44$-positive cells had retained more EdU than CSC480 cells at the same time-point (65.48 and $38.89 \%$, respectively).

\section{Discussion}

In recent years, it has become apparent that CSCs are one of the main factors contributing to tumor development and metastasis and there has been considerable effort invested in 
A

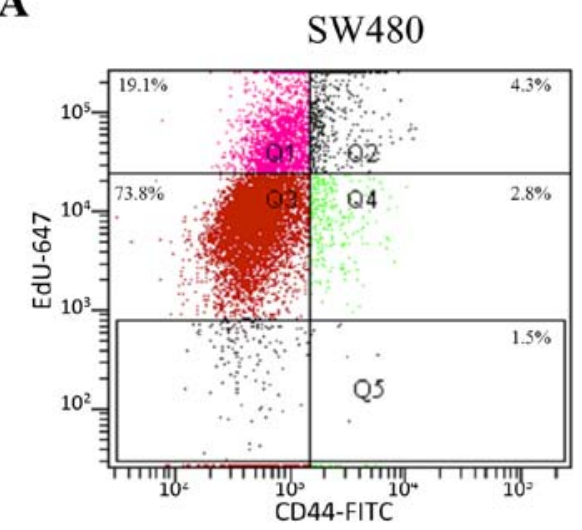

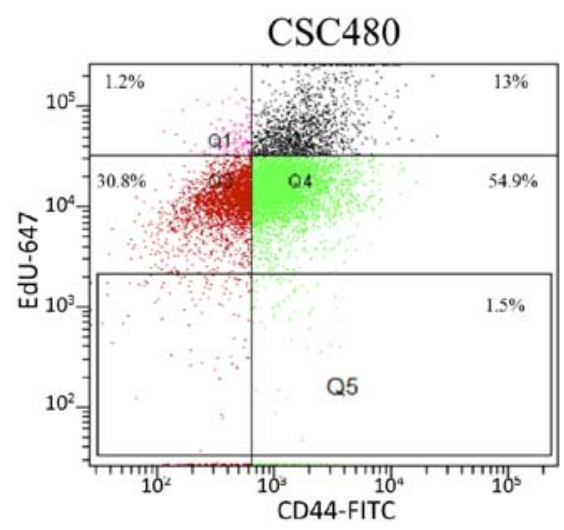

B DAPI CD44
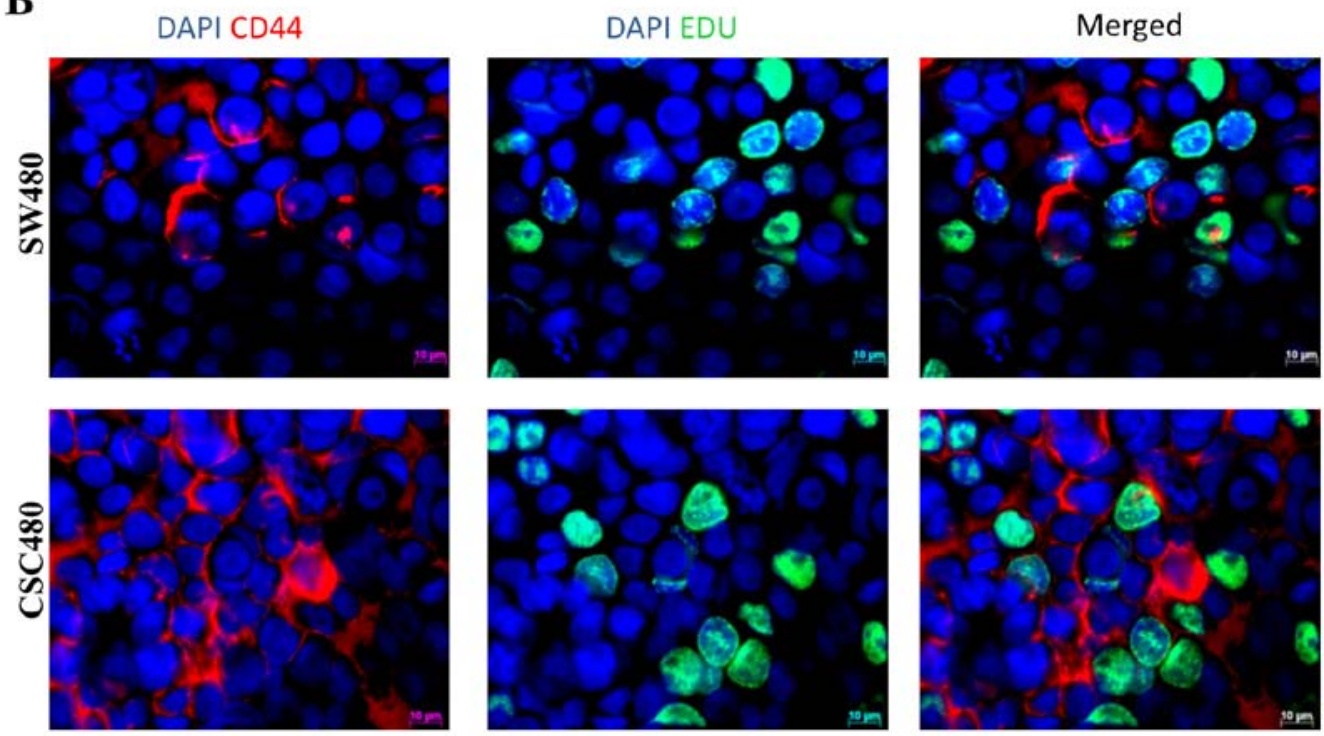

Figure 5. Identifying CD44-positive populations in SW480 and CSC480 cancer cell lines. (A) Flow cytometric analysis of CD44-positive populations using thymidine analogue EdU in SW480 (scatter plot on left) and CSC480 cells (scatter plot on right) is presented. Q1, EdU ${ }^{\text {high }} / \mathrm{CD} 44^{\text {low }}$ (19.1\% for SW480 and $1.2 \%$ for CSC480); Q2, EdU ${ }^{\text {high }} / C D 44^{\text {high }}$ (4.3\% for SW480 and 13\% for CSC480); Q3, EdU ${ }^{\text {low-mid }} / C D 44^{\text {high }}$ (73.8\% for SW480 and 30.8\% for CSC480); Q4, EdU ${ }^{\text {low }} / \mathrm{CD} 44^{\text {high }}$ (2.8\% for SW480 and $54.9 \%$ for CSC480); Q5, CD44 ${ }^{\text {high }}$ (1.5\% for both SW480 and CSC480). (B) Identification of CD44 and EdU-positive cell populations. Immunofluorescence images of CD44-positive and EdU-positive cell populations in CSC480 and SW480 cell lines are shown. Anti-CD44 (red), EdU-positive (green) and cell nucleus (DAPI, blue), right panel, merged images. Top row, SW480 cells; bottom row, CSC480 cells, images captured at x63 magnification.

understanding and characterising this enigmatic cell population. However, these efforts have been restrained by several factors. The lack of a cancer stem-cell model that recapitulates the actual CSC population present in cancer tissues is considered one of the main obstacles. Furthermore, the absence of a specific biomarker that unarguably identifies a pure CSC population has rendered in vivo characterisation difficult. The method of identifying and purifying CSCs in different organs depends largely on their surface phenotype and use of flow cytometry.

Adequate number of CSCs that have stable phenotypes and similar backgrounds are required to perform reliable functional assays. However, CSCs isolated from patients are generally rare and readily differentiate in culture and as a consequence, a shortage in material for functional assessment or for screening new agents specific to CSCs persists (23). Most CSC assays depend on the enrichment of CSCs from freshly isolated tumors and the efficiency of cell sorting and varied genetic background can also hinder CSC research. Furthermore, freshly isolated cancer stem-like cells can be contaminated with lymphocytes or stromal cells that affect the downstream assessment. Thus, the establishment of human CSC lines is a desirable strategy to investigate the mechanisms of tumor initiation, resistance to novel treatment regimens, metastasis and recurrence (23).

Therefore, efforts to establish CSC lines have been a landmark in cancer research. These efforts varied from transient enrichment using specific growth factors as non-adherent spheres, to using induced pluripotent stem cell (iPSC) technology to reprogram gastrointestinal cancer cells by introducing embryonic stem (ES) cells transcription factors (24).

The main aim of the present study was to analyse and characterise the novel putative cancer 'stem' cell line CSC480. These cells have not been previously studied and very limited information was available concerning their behaviour. Furthermore, it was not clear how these cells were enriched and no information was available about the conformation of their stemness. To address these gaps in knowledge and to unravel the nature of CSC480 cells, they were subjected to thorough analyses using cellular and molecular assays. We used CD44 
A

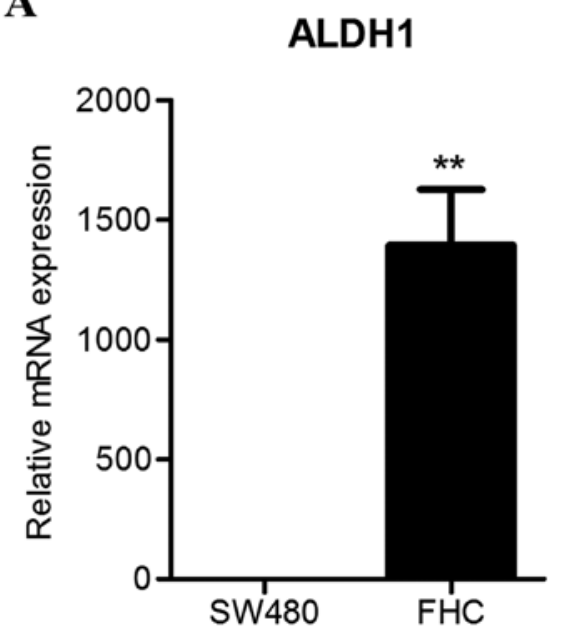

B

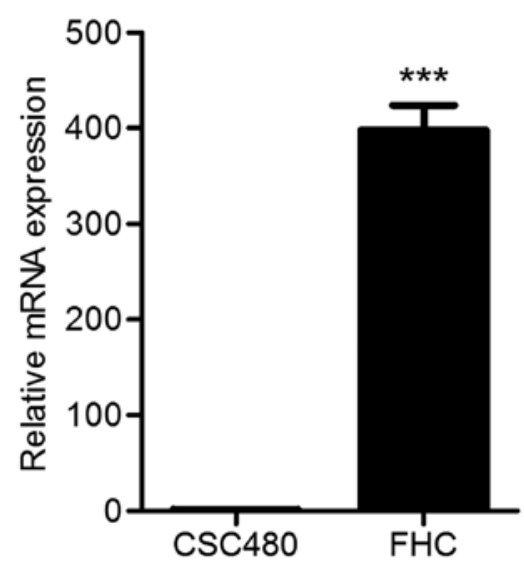

Figure 6. Assessing the self-renewal capacity of cancer cells using ALDH1 as a marker. (A) The expression of ALDH1 mRNA levels in FHC cells compared to SW480 as a marker for self-renewal capacity for cancer cells. (B) The expression of ALDH1 mRNA levels in FHC cells compared to CSC480 cells. Data are mean \pm SEM, $n=3$; statistical analysis, Student's t-test; ${ }^{* *} \mathrm{P}<0.01,{ }^{* * *} \mathrm{P}<0.001$, respectively.

and ALDH1A1 markers to assess the stemness/progenitor-like properties of these cells. CSC480 cells revealed increased expression of CD44 and ALDH1 compared to SW480 cancer cell line. CD44, a highly heterogeneous glycoprotein encrypted by a single gene, is involved in multiple cellular mechanisms including cellular migration, adhesion and proliferation. Furthermore, it is pro-oncogenic and acts as a regulator of multiple pathways as demonstrated in breast cancer (25). CD44 is represented by two isoforms. The standard isoform, which is expressed by the mesenchymal and hematopoietic cells, while epithelial cells express the variant isoform. CD44 variant overexpression in head and neck squamous cell carcinoma is associated with invasion, clinical stage, therapeutic resistance and relapse (26). Thus, CD44 may be a reliable marker for tumor progression assessment. CD44 has also been used to mark and isolate CSCs from a range of malignant tumors, including breast (27) and colon (28) cancers. However, it is insufficient to use CD44 as a stand-alone marker of CSCs as sometimes CD44-positive populations are heterogeneous (29).

The present study demonstrated that almost all CSC480 cells express CD44 marker. Thus, we used EdU to identify different
$\mathbf{A}$

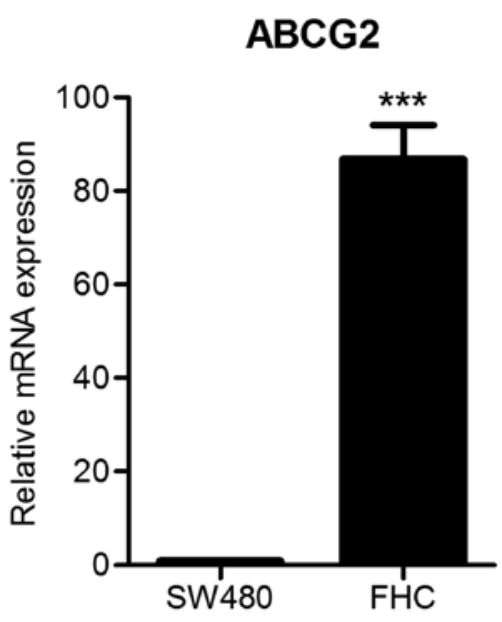

B

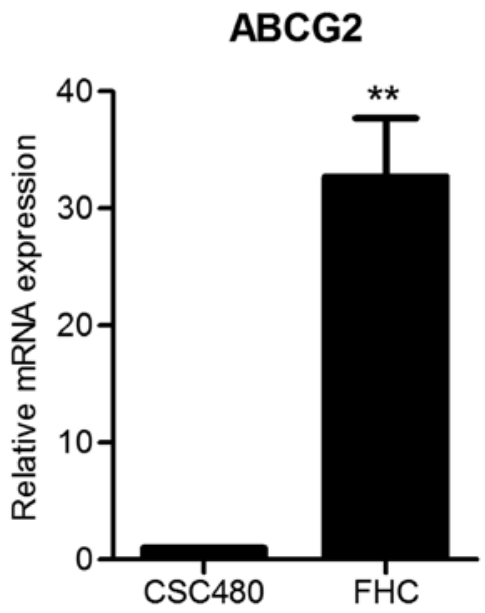

Figure 7. Assessing ABCG2 mRNA expression as an indicator to cancer resistance in cancer cell lines. (A) Bar graph represents the expression of ABCG2 mRNA levels in FHC cells and SW480 cancer cells. (B) Bar graph represents the expression of ABCG2 mRNA expression levels in FHC cells and CSC480 cancer cells. Data are mean \pm SEM, $n=3$; statistical analysis, Student's t-test; ${ }^{* *} \mathrm{P}<0.01,{ }^{* * *} \mathrm{P}<0.001$.

CD44-positive populations by flow cytometry. It was also used to assess their proliferation capacity and their quiescence status. Assessing the proliferation and identifying cells resting in dormant state were previously reported $(22,30)$. EdU is a nucleoside analogue of thymidine that would be incorporated into DNA during DNA synthesis phase (30). We employed this feature in the present study to identify different populations present in CSC480 cells based on the DNA division state. This technique revealed that EdU labels CSC480 CD44-positive cells with different intensities according to DNA division rate. Four CD44 stained populations were labelled with EdU, while only a minor subset of cells was positive for CD44 alone. This EdU-negative and CD44-positive population may represent the non or slow-dividing cells. We observed that EdU was able to segregate SW480 cells into similar populations as well. This indicated that EdU may be used to identify different populations in a heterogeneous cancer population. This may have an impact on identifying cancer cell populations based on their division status, which may help in deciding therapeutic regimens and defining the percentage of actively dividing cells compared to dormant cells. Furthermore, based on the 


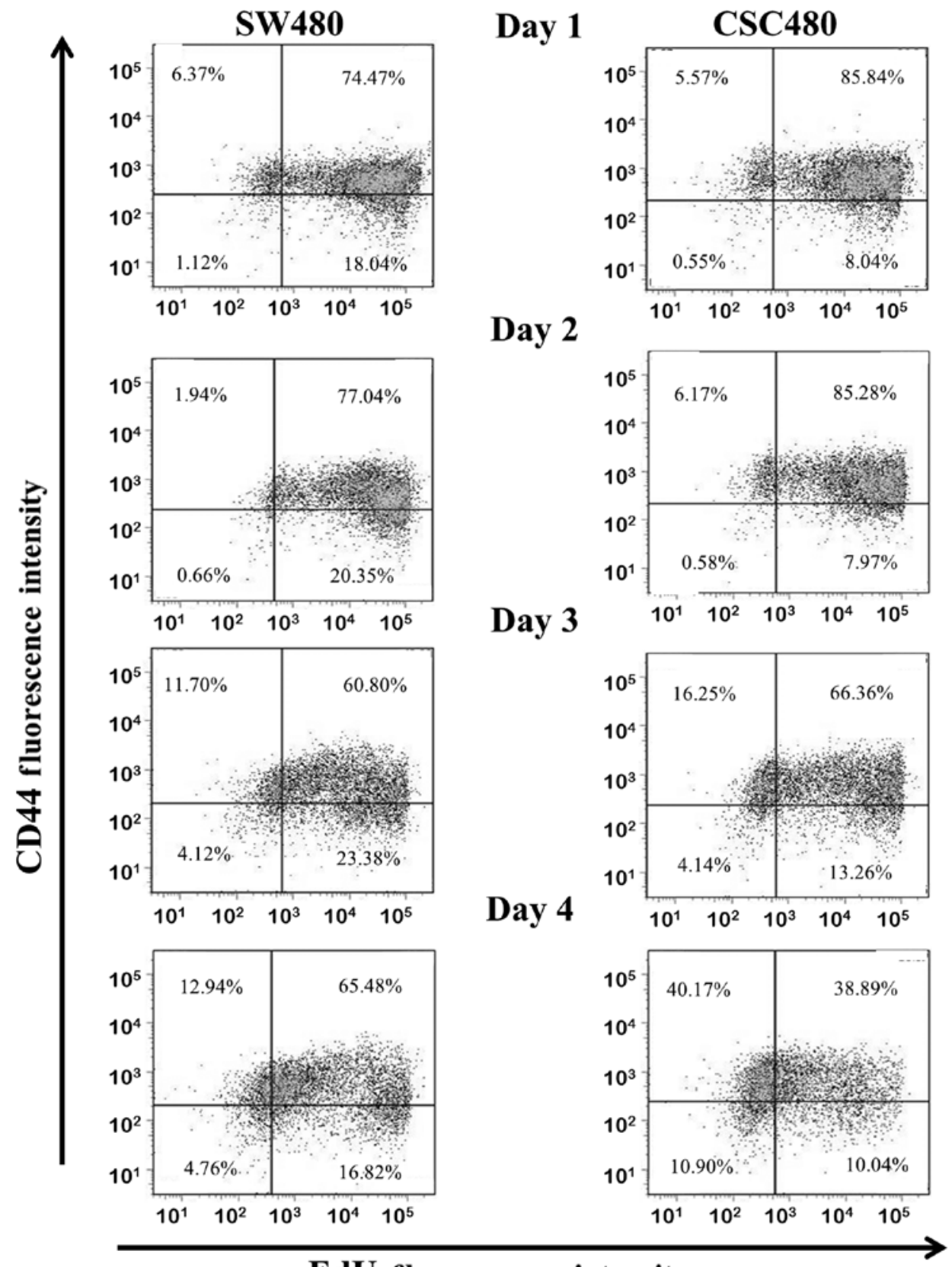

EdU fluorescence intensity

Figure 8. Label retaining cell assay for identifying dormant cancer cells. Scatter plot represents both CD44 and EdU fluorescence staining on SW480 and CSC480 cancer cell lines. SW480 and CSC480 cells were pulsed with EdU and collected on day 1,2,3 and 4 post pulse. The cells were then subjected to click chemistry for detection of EdU followed by incubation with anti-CD44 antibody. Subsequently, the cells were analysed for label retention of EdU vs. CD44 fluorescence immunostaining.

reported findings by Deleyrolle et al (22), we hypothesised that EdU could be used as a LRC marker. The cells that are actively dividing will dilute the label during multiple rounds of divisions. After a certain period of time (chase period), the cells will end up having no detectable label. Conversely, cells in slow division retain the label (31). Thus, the CSC480 dormant population was analysed by combining CD44 with EdU after exposing cells to EdU for $24 \mathrm{~h}$. Our hypothesis implied that cells retaining EdU would be CD44-positive. Subsequently, we subjected pulsed cells for the analysis after collecting them at different time-points and we found that cells lost their EdU content according to their number of divisions (Fig. 8). However, not all cells that retained EdU were CD44-positive.
Furthermore, more SW480 cells retained EdU on day 4 than CSC480 cells. This raised the question whether label-retaining assays were suitable to identify dormant stem cell populations, even though they provided a valuable tool to delineate the cycling properties within a given population. However, caution should be taken in consideration when designing and interpreting these experimental results. Firstly, although many stem cells are slow cycling, label-retention on its own does not indicate 'stemness'. In some cases, cells dividing during the pulse period, withdrawn from the cell cycle and differentiated will also appear as LRCs (31). The more 'differentiated' cell line, SW480 has been found to have some LRC that were not CD44-positive. Furthermore, the extremely slow cycling cells 
may not incorporate EdU during pulse window and as a result may be missed during the assessment process (31). To accurately assess the cycling status of a given cell, EdU should be combined with a cell cycle kinetic marker in addition to CD44.

CSC480 cells demonstrated increased expression of ABCG2, a cancer-resistance protein, compared to SW480 cells. Resistance to chemotherapy has been the most important characteristic feature of CSCs and the main reason for cancer metastasis and recurrence (32). The enrichment of breast CSCs post-chemotherapy, has been reported as an indicator of resistance to chemotherapy (33).

CSC480 cells were found to equally express NANOG compared to the SW480 parental cell line. This may be an indicator that CSC480 cell line represented partly self-renewing progenitor cells. NANOG has been revealed as an indispensable component in transforming gastrointestinal cancer cells into pluripotent stem cells (24).

Epithelial cell adhesion molecule (EpCAM) showed up to 2,500 and 1,500-fold increased expression in SW480 and CSC480 cells, respectively compared to FHC normal epithelial cells. This marker has been revealed to be widely expressed in epithelial tissue and all colorectal cancer cells $(34,35)$. A previous study (36) demonstrated that EpCAM regulated self-renewal in colon initiating cells. It was also delineated in the same study, that the persistence of EpCAM expression was linked with increased invasiveness in vitro and tumor initiating capacity in vivo. Furthermore, its increased expression was correlated with increased expression of stemness markers like OCT4, NANOG and c-Myc in colon cancer (36).

The present study has also revealed that the fetal human colon cell line, FHC, highly expressed ALDH1 in comparison to SW480 and CSC480 cancer cell lines. FHC cells are featured by their extremely slow division as observed in the present study. Thus, the increased expression of ALDH1 in FHC cells may provide evidence that it marked slow (dividing) cycling cells. Furthermore, elevated expression of ABCG2 was also observed in FHC cells compared to SW480 and CSC480 cells. This may confirm the reported feature that dormant cells resist chemotherapy (37). FHC cells exhibited resistance to apoptosis after genotoxic treatment (37). When FHC cells were pulsed with EdU, none of the cells demonstrated EdU labelling (data not shown). This finding indicated that many FHC cells may reside in a dormant state. Assessing FHC cells in terms of tumorigenicity, revealed that these cells are capable of growing in semisolid media under anchorage-independent growth conditions in vitro and have exhibited a capacity to form solid tumors in vivo (37).

Based on these findings, we analysed SW480 and CSC480 cell gene expression using ALDH1 and ABCG2 and observed that the CSC480 cell line exhibited elevated expression compared to SW480 cells. This implied that CSC480 cells contained more cancer stem-like cells that were resistant to chemotherapy in comparison to SW480 cells, which needed to be determined experimentally. Collectively, FHC cells could be considered as an indispensable experimental model for assessing quiescence markers for identifying dormant cancer stem-like cells and as a positive control for examining chemotherapeutic drugs.

In the present study, we examined a number of putative CSC characteristics in CSC480 cells compared to other well-established cell lines. Since CSC480 is a newly reported cell line and the present study was the first, further characterization at the in vitro level should be considered to define these cells. Assessing the molecular and phenotypic profile of certain known colorectal stemness signature like Lrg5, BIM-1 and c-MYC should be undertaken. Furthermore, identifying the self-renewal capacity using clonal limited dilution assay should also be pursued, as should in vivo growth assessment by inoculating a limited number of cells subcutaneously compared with other cancer cell lines. Cancer resistance to ABCG2 could be examined using a range of drugs that are shown to be effluxed by ABCG2 such as mitoxantrone and methotrexate (38).

In conclusion, CSC480 cells were composed of a high percentage of transiently dividing and self-renewing cells and CD44 appeared to be a marker for these partially self-renewing precursor cells.

\section{Acknowledgements}

Not applicable.

\section{Funding}

The present study was supported by a PhD scholarship awarded to F.A. by King Saud University. In addition, the present study was supported by the 'College of Medicine Research Centre, Deanship of Scientific Research, King Saud University'.

\section{Availability of data and materials}

The datasets used during the present study are available from the corresponding authors upon reasonable request.

\section{Authors' contributions}

FA contributed to the study design, experimental work and manuscript write up; SMH contributed to the study design, experimental work and manuscript revision; NA contributed to experimental work and the manuscript; RA contributed to the experimental work; SI contributed to the revision of the manuscript; BB contributed to the experimental work; AM and AL contributed to the experimental design; SW contributed to the design and revision of the manuscript. All authors read and approved the manuscript and agree to be accountable for all aspects of the research in ensuring that the accuracy or integrity of any part of the work are appropriately investigated and resolved.

\section{Ethics approval and consent to participate}

Not applicable.

\section{Consent for publication}

Not applicable.

\section{Competing interests}

The authors declare that they have no competing interests. 


\section{References}

1. Dittmar T, Nagler C, Schwitalla S, Reith G, Niggemann B and Zänker KS: Recurrence cancer stem cells-made by cell fusion? Med Hypotheses 73: 542-557, 2009.

2. Yang ZJ and Wechsler-Reya R: Hit'em where they live: Targeting the cancer stem cell niche. Cancer Cell 11: 3-5, 2007.

3. Shen C, Xiang M, Nie C, Hu H, Ma Y and Wu H: CD44 as a molecular marker to screen cancer stem cells in hypopharyngeal cancer. Acta Otolaryngol 133: 1219-1226, 2013.

4. Misra S, Toole BP and Ghatak S: Hyaluronan constitutively regulates activation of multiple receptor tyrosine kinases in epithelial and carcinoma cells. J Biol Chem 281: 34936-34941, 2006.

5. Ghatak S, Misra S and Toole BP: Hyaluronan constitutively regulates ErbB2 phosphorylation and signaling complex formation in carcinoma cells. J Biol Chem 280: 8875-8883, 2005.

6. Kim HR, Wheeler MA, Wilson CM, Iida J, Eng D, Simpson MA, McCarthy JB and Bullard KM: Hyaluronan facilitates invasion of colon carcinoma cells in vitro via interaction with CD44. Cancer Res 64: 4569-4576, 2004.

7. Du L, Wang H, He L, Zhang J, Ni B, Wang X, Jin H, Cahuzac N, Mehrpour M, Lu Y and Chen Q: CD44 is of functional importance for colorectal cancer stem cells. Clin Cancer Res 14 6751-6760, 2008.

8. Jones RJ, Barber JP, Vala MS, Collector MI, Kaufmann SH, Ludeman SM, Colvin OM and Hilton J: Assessment of aldehyde dehydrogenase in viable cells. Blood 85: 2742-2746, 1995.

9. Armstrong L, Stojkovic M, Dimmick I, Ahmad S, Stojkovic P, Hole $\mathrm{N}$ and Lako M: Phenotypic characterization of murine primitive hematopoietic progenitor cells isolated on basis of aldehyde dehydrogenase activity. Stem Cells 22: 1142-1151, 2004.

10. Storms RW, Green PD, Safford KM, Niedzwiecki D, Cogle CR Colvin OM, Chao NJ, Rice HE and Smith CA: Distinct hematopoietic progenitor compartments are delineated by the expression of aldehyde dehydrogenase and CD34. Blood 106: 95-102, 2005.

11. Matsui W, Huff CA, Wang Q, Malehorn MT, Barber J, Tanhehco Y, Smith BD, Civin CI and Jones RJ: Characterization of clonogenic multiple myeloma cells. Blood 103: 2332-2336, 2004.

12. Pearce DJ, Taussig D, Simpson C, Allen K, Rohatiner AZ, Lister TA and Bonnet D: Characterization of cells with a high aldehyde dehydrogenase activity from cord blood and acute myeloid leukemia samples. Stem Cells 23: 752-760, 2005.

13. Naumov GN, Bender E, Zurakowski D, Kang SY, Sampson D, Flynn E, Watnick RS, Straume O, Akslen LA, Folkman J and Almog N: A model of human tumor dormancy: An angiogenic switch from the nonangiogenic phenotype. J Natl Cancer Inst 98 316-325, 2006

14. $\mathrm{Yu} \mathrm{Y}$ and $\mathrm{Zhu} \mathrm{Z}$ : Cell dormancy and tumor refractory. Anticancer Agents Med Chem 13: 199-202, 2013.

15. Quesnel B: Tumor dormancy: Long-term survival in a hostile environment. Adv Exp Med Biol 734: 181-200, 2013.

16. Wells A, Griffith L, Wells JZ and Taylor DP: The dormancy dilemma: Quiescence versus balanced proliferation. Cancer Res 73: 3811-3816, 2013.

17. Kleffel $\mathrm{S}$ and Schatton T: Tumor dormancy and cancer stem cells: Two sides of the same coin? Adv Exp Med Biol 734: 145-179, 2013.

18. Duvillié B, Attali M, Aiello V, Quemeneur E and Scharfmann R: Label-retaining cells in the rat pancreas: Location and differentiation potential in vitro. Diabetes 52: 2035-2042, 2003.

19. Diermeier-Daucher S, Clarke ST, Hill D, Vollmann-Zwerenz A, Bradford JA and Brockhoff G: Cell type specific applicability of 5-ethynyl-2'-deoxyuridine (EdU) for dynamic proliferation assessment in flow cytometry. Cytometry A 75: 535-546, 2009.

20. Qian Y: Tumorigenic cancerstemcells, methods of isolating and using the same. Google Patents, US20110206735: 2011.

21. Wang S, Kanojia D, Lo P, Chandrashekaran V, Duan X, Berger FG, Wang Q and Hexin C: Enrichment and selective targeting of cancer stem cells in colorectal cancer cell lines. Hum Genet Embryol S2: 006, 2012.
22. Deleyrolle LP, Harding A, Cato K, Siebzehnrubl FA, Rahman M, Azari H, Olson S, Gabrielli B, Osborne G, Vescovi A and Reynolds BA: Evidence for label-retaining tumour-initiating cells in human glioblastoma. Brain 134: 1331-1343, 2011.

23. Rao GH, Liu HM, Li BW, Hao JJ, Yang YL, Wang MR, Wang XH, Wang J, Jin HJ, Du L and Chen Q: Establishment of a human colorectal cancer cell line P6C with stem cell properties and resistance to chemotherapeutic drugs. Acta Pharmacol Sin 36: 793-804, 2013

24. Miyoshi N, Ishii H, Nagai K, Hoshino H, Mimori K, Tanaka F, Nagano H, Sekimoto M, Doki Y and Mori M: Defined factors induce reprogramming of gastrointestinal cancer cells. Proc Natl Acad Sci USA 107: 40-45, 2010.

25. Smith SM and Cai L: Cell specific CD44 expression in breast cancer requires the interaction of $\mathrm{AP}-1$ and $\mathrm{NFKB}$ with a novel cis-element. PLoS One 7: e50867, 2012.

26. Wang SJ, Wong G, de Heer AM, Xia W and Bourguignon LY: CD44 variant isoforms in head and neck squamous cell carcinoma progression. Laryngoscope 119: 1518-1530, 2009.

27. Al-Hajj M, Wicha MS, Benito-Hernandez A, Morrison SJ and Clarke MF: Prospective identification of tumorigenic breast cancer cells. Proc Natl Acad Sci USA 100: 3983-3988, 2003.

28. Dalerba P, Dylla SJ, Park IK, Liu R, Wang X, Cho RW, Hoey T, Gurney A, Huang EH, Simeone DM, et al: Phenotypic characterization of human colorectal cancer stem cells. Proc Natl Acad Sci USA 104: 10158-10163, 2007.

29. Ricardo S, Vieira AF, Gerhard R, Leitão D, Pinto R, Cameselle-Teijeiro JF, Milanezi F, Schmitt F and Paredes J: Breast cancer stem cell markers CD44, CD24 and ALDH1: Expression distribution within intrinsic molecular subtype. J Clin Pathol 64: 937-946, 2011.

30. Buck SB, Bradford J, Gee KR, Agnew BJ and Clarke ST: Detection of S-phase cell cycle progression using 5-ethynyl-2'-deoxyuridine incorporation with click chemistry, an alternative to using 5-bromo-2'-deoxyuridine antibodies. Biotechniques 44: 927-929, 2008.

31. Hsu YC and Fuchs E: A family business: Stem cell progeny join the niche to regulate homeostasis. Nat Rev Mol Cell Biol 13: 103-114, 2012.

32. Ding XW, Wu JH and Jiang CP: ABCG2: A potential marker of stem cells and novel target in stem cell and cancer therapy. Life Sci 86: 631-637, 2010.

33. Lee HE, Kim JH, Kim YJ, Choi SY, Kim SW, Kang E, Chung IY, Kim IA, Kim EJ, Choi Y, et al: An increase in cancer stem cell population after primary systemic therapy is a poor prognostic factor in breast cancer. Br J Cancer 104: 1730-1738, 2011.

34. Butler SJ, Richardson L, Farias N, Morrison J and Coomber BL: Characterization of cancer stem cell drug resistance in the human colorectal cancer cell lines HCT116 and SW480. Biochem Biophys Res Commun 490: 29-35, 2017.

35. Trzpis M, McLaughlin PM, de Leij LM and Harmsen MC: Epithelial cell adhesion molecule: More than a carcinoma marker and adhesion molecule. Am J Pathol 171: 386-395, 2007.

36. Lin CW, Liao MY, Lin WW, Wang YP, Lu TY and Wu HC: Epithelial cell adhesion molecule regulates tumor initiation and tumorigenesis via activating reprogramming factors and epithelial-mesenchymal transition gene expression in colon cancer. J Biol Chem 287: 39449-39459, 2012.

37. Souček K, Gajdušková P, Brázdová M, Hýzd'alová M, Kocí L, Vydra D, Trojanec R, Pernicová Z, Lentvorská L, Hajdúch M, et al: Fetal colon cell line FHC exhibits tumorigenic phenotype, complex karyotype, and TP53 gene mutation. Cancer Genet Cytogenet 197: 107-116, 2010.

38. Doyle L and Ross DD: Multidrug resistance mediated by the breast cancer resistance protein BCRP (ABCG2). Oncogene 22 : 7340-7358, 2003. 